\title{
Exclusive breastfeeding in rural Western China: does father's co-residence matter?
}

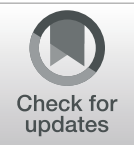

Jingchun Nie ${ }^{1}$, Lifang Zhang ${ }^{2}$, Shuyi Song ${ }^{1}$, Andrew John Hartnett ${ }^{3}$, Zhuo Liu' ${ }^{1}$, Nan Wang ${ }^{1}$, Weiqi Nie ${ }^{1}$, Jie Yang ${ }^{1 *}$, Ying $\mathrm{Li}^{1}$ and Yaojiang Shi ${ }^{1}$

\begin{abstract}
Background: China suffers from a low exclusive breastfeeding rate. Though it has been proofed that paternal support benefits breastfeeding a lot, the correlation between father's co-residence and exclusive breastfeeding in China remain undiscovered. This study is to provide population-based evidence for the association of paternal coresidence on exclusive breastfeeding in rural western China. We also attempt to detect how the process works by examining the correlation between the father's co-residence and breastfeeding family support as well as maternal decision-making power.
\end{abstract}

Methods: A cross-sectional study was conducted in 13 nationally-designated poverty-stricken counties in the Qinba Mountains area in 2019. Data on breastfeeding practices, the status of fathers co-residence, breastfeeding family support, and maternal decision-making power were collected via structured questionnaires from 452 caregiversinfant pairs. Multivariate regressions were conducted to explore the correlation between paternal co-residence and exclusive breastfeeding.

Results: The exclusive breastfeeding (0-6 months) rate was 16\% in rural western China. Fathers' co-residence was associated with a lower exclusive breastfeeding rate $(O R=0.413,95 \% \mathrm{Cl}=0.227-0.750, P=0.004)$ and the rate did not improve when the father was the secondary caregiver. Even ruling out support from grandmothers, the association was still negative. Paternal co-residence did not improve maternal perceived breastfeeding family support, neither practically nor emotionally $(\beta=0.109, P=0.105 ; \beta=0.011, P=0.791$, respectively $)$ and it reduced maternal decision-making power $(\beta=-0.196, P=0.007)$.

Conclusions: Fathers' co-residence is negatively associated with the exclusive breastfeeding rates in rural western China. More skill-based practical and emotional strategies should be considered on father's education to help them better involvement and show more respect to mothers' decisions.

Keywords: Exclusive breastfeeding, Breastfeeding family support, father's co-residence, Rural western China, Maternal decision-making power

\footnotetext{
*Correspondence: jyang0716@163.com

${ }^{1}$ Center for Experimental Economics in Education, Shaanxi Normal University,

No. 620 West Chang'an Street, Chang'an District, Xian, Shaanxi Province,

China

Full list of author information is available at the end of the article
}

(c) The Author(s). 2021 Open Access This article is licensed under a Creative Commons Attribution 4.0 International License, which permits use, sharing, adaptation, distribution and reproduction in any medium or format, as long as you give appropriate credit to the original author(s) and the source, provide a link to the Creative Commons licence, and indicate if changes were made. The images or other third party material in this article are included in the article's Creative Commons licence, unless indicated otherwise in a credit line to the material. If material is not included in the article's Creative Commons licence and your intended use is not permitted by statutory regulation or exceeds the permitted use, you will need to obtain permission directly from the copyright holder. To view a copy of this licence, visit http://creativecommons.org/licenses/by/4.0/. The Creative Commons Public Domain Dedication waiver (http://creativecommons.org/publicdomain/zero/1.0/) applies to the data made available in this article, unless otherwise stated in a credit line to the data. 


\section{Background}

Compelling evidence shows that breastfeeding provides numerous benefits for both infants and mothers, including fewer infections for infants and less chance of breast cancer, ovarian cancer and type 2 diabetes for mothers [1]. Many countries including China cite the improvement of breastfeeding as a major public health issue [2]. However, China still suffers from a low exclusive breastfeeding rate for the first 6 month ranging from 20 to $30 \%$ in both urban and rural areas [3, 4]. With a growing number of women being employed, inadequate paid maternity leave and unsupportive work environments are major contributors to the low exclusive breastfeeding rate worldwide $[5,6]$. However, mothers in rural areas either cease to migrate to cities for works or being unemployed during the first few months of newborns, ${ }^{1}$ which enables mothers to stay with infants all the time and feed them on demand. So the low exclusive breastfeeding rate must be caused by some other factors. Further, 138 million children live in rural China and nearly half of them are in poor areas [7]. Understanding the exclusive breastfeeding practice in rural China are essential for those children to get adequate nutrition, and for Chinese government to achieve the exclusive breastfeeding rate target of $50 \%$ by 2020 [8].

Determinants of breastfeeding have been studied widely, such as caesarean section rate, maternal education, family income and paternal involvement [4, 9-11]. Of these influential factors, paternal support is less discussed in the context of China rural areas, where a majority of fathers are rarely co-resident in the household but migrating to cities for work. Dozens of previous researches have documented the importance of paternal support on successful breastfeeding practice [12-15]. Paternal practical support includes taking care of infants and assisting with household chores, such as helping to burp the baby, changing diapers, washing clothes, and is quite supportive for earlier breastfeeding initiation and longer breastfeeding duration [12, 16]. Paternal emotional support, including encouragement, compliments, affection and reassurance at difficult moments, is also an essential ingredient to successful breastfeeding, which increases mother's confidence and enables her to maintain an adequate milk supply [10, 17, 18].

Barrier of providing paternal support may exist in rural areas of China where fathers are not co-resident with their spouses. Statistics showed that male labors fluxed to urban areas have reached 79.18 million in 2018 in this area, accounting for $28 \%$ of the total national migrate labor [19]. More than half of the children (56\%)

\footnotetext{
${ }^{1}$ In our ample, over $90 \%$ mothers' main job is to look after their infants currently; others, need to do some housework, but no one is employed at that time.
}

under 3 years old live in western rural areas with their fathers being absent [20]. Therefore, we select rural western China to explore the association of father's coresidency and exclusive breastfeeding rate.

The assumption that father's co-residence is positively associated with exclusive breastfeeding may oversimplify the situation. Though fathers will have more chance to take care of mothers and infants when they are living at home, they may rarely do so. On one hand, since fathers are shouldering the main financial responsibility of the whole family, they need to do farm work as well as some part-time job into cover the daily expense which may make them too exhausted to provide their support on breastfeeding [21]. On the other hand, old generation, particularly the infant's grandmothers, are regarded as a main source of breastfeeding family support, especially when lacking of learning materials and community consultants [22-24]. However, father's co-residence may crowd out the support from grandmothers who are more experienced, thus impair the exclusive breastfeeding practices. Moreover, research suggests that fathers in rural areas tend to be low-educated and less knowledgeable about exclusive breastfeeding [25-27] and less adept at comforting mothers in feeding problems or expressing encouragement and praise for mother's greatness due to gender norms [21]. To clarify these guesses, it is important to examine the association of father's co-residence on exclusive breastfeeding. Limitations also exist in methodology of previous studies about exclusive breastfeeding in rural China, such as small and convenience sample instead of representative sample sizes [17, 28, 29]. Therefore, population-based evidence from rural China is crucial to bridge this gap.

Apart from providing breastfeeding family support, father's co-residence may have an additional impact on reducing maternal decision-making power, which is examined as a determinant of infants health and nutrition [30, 31]. In rural areas of China, women are still in a relatively weak position in terms of family decisionmaking [32, 33]. It is even more so when fathers were involved in baby care. However, evidence showed that women with more decision-making power were associated with longer breastfeeding duration, more dietary diversity and less child stunting [31, 34, 35], which can help improve infants' health and nutrition status.

Above all, the objective of this study is to provide population-based evidence of the influence of father's co-residence on exclusive breastfeeding in western rural China. Furthermore, we try to understand how the process works by examining the correlation of the father's co-residence on breastfeeding family support and maternal decision-making power. This study will enrich literature on the relationship between father's coresidence and exclusive breastfeeding, thereby raising 
important implications for public policy to encourage fathers' involvement in parenting and to promote exclusive breastfeeding in rural China.

\section{Methods \\ Setting}

This study was conducted in two prefecture-level cities from the Qinba Mountains area. The Qinba Mountains area spans six provinces of western China located in Qinling and Bashan Mountains, which is one of the eight multidimensional Poverty in Regions of Contiguous Distress [36]. At the end of 2018, there was 1.97 million poverty-stricken population in this entire region which accounted for $11.9 \%$ of the national population of poor people, and 67 nationally-designated poverty-stricken counties which comprised $11.4 \%$ of the nation total poverty-stricken counties in China [36, 37]. Within the Qinba Mountains area, nearly half of them live in the countryside [37]. Our data collection was conducted in 13 nationally-designated poverty-stricken counties from two prefecture-level cities in this area.

\section{Sample}

The inclusion criteria of the study were: (a) the infant had been a resident of the sample village after delivery; (b) the infant was aged between 0 and 6 months ( 0 to 180 days) old. The exclusion criteria were: (a) the primary caregiver was not the mother; (b) the primary caregiver had cognitive impairment; (c) parents of the infant divorced or at least one parent died. We recognized those as cognitive disorders who cannot understand our structural questionnaire after repeating for three times and checked the condition with their family. Respondents included the primary caregiver (mother) and secondary caregiver (the person who spends the most time and efforts in taking care of the infants except for the primary caregiver, usually the father or grandparent) of the infant.

The sample size was estimated to achieve, for a binomial variable of 0.15 in consideration of our pilot finding, a standard error of 0.025 with a 95\% confidence interval of $0.10-0.20$. The final desired sample size was 430.

Cluster random sampling was used to select participants following three steps. First, we got the village list from local health commissions and randomly selected half of the rural villages from each of the 13 counties, which constitute our initial sample frame of 876 villages. Then we acquired the newborn list from local health commissions and checked the list with the primary healthcare providers in each village, who are responsible for managing the newborns in the village. We excluded villages with fewer than 3 or more than 15 eligible participants with a comprehensive consideration of research costs and power requirements, after which 202 villages were eligible to be included in final sample frame. We used Stata 15.0 (Stata Corp, College Station, TX) to generate random numbers and obtained 131 sample villages from the eligible villages based on the sample size calculation. Finally, in each of the 131 eligible villages, all caregivers-infant pairs meeting our inclusion criteria above were included, thus constituted a total number of 467 eligible caregivers-infant pairs representing Qinba Mountains area. Of these, 10 caregivers-infant pairs were excluded because mothers were not the first caregivers of infants and 5 were excluded because of missing data. Finally, 452 caregivers-infant pairs were included in the analysis.

\section{Data collection}

Data was collected in March 2019. With the assistance of the local healthcare provider in each village, a consent form with information about program objectives, procedure, potential risks and benefits, as well as privacy protection was distributed to each eligible participant before the face-to-face interview by one enumerator. To ensure accuracy and consistency during the procedure of data collection, the enumerators were trained intensively, followed by a simulation exercise with twenty participants prior to data collection. The questions were shown in tablet and asked one by one by the enumerator while answers recording timely. After the interview with the mother, a short questionnaire was given to the secondary caregiver as well. Each interview was conducted alone to avoid interruptions from others.

\section{Measurements}

\section{Demographics}

Demographic information was collected from the primary caregiver (the mother) about the infant's gender, age (based on the number of days), method of delivery, small for gestation age (SGA), preterm delivery (gestational age $<37$ weeks) or not, as well as other personal information about the caregiver including maternal age and education level, number of siblings and the ownership of nine selected family asset items. Caregivers' nutrition and health knowledge was also assessed according to their responses on eight questions about infant's health and the benefits of exclusive breastfeeding. We calculated the total score as a measurement of their nutrition and health knowledge. We also asked who the secondary caregiver of the infant was.

Father's co-residence is the independent variable of interest. It was coded as " 1 " if the father living at home when the survey was conducted, and " 0 " if the father is absent.

Exclusive breastfeeding is the main outcome of interest. The feeding practices of infants within the last $24 \mathrm{~h}$ 
Table 1 Characteristics of infants living with or without fathers

\begin{tabular}{|c|c|c|c|c|}
\hline \multirow[t]{2}{*}{ Characteristics } & (1) & $(2)$ & (3) & (4) \\
\hline & $\begin{array}{l}\text { Full sample } \\
n 1=452 \\
\text { No.(\%) or Mean(SD) }\end{array}$ & $\begin{array}{l}\text { Living with father } \\
\mathrm{n} 2=242 \\
\text { No.(\%) or Mean(SD) }\end{array}$ & $\begin{array}{l}\text { Living without father } \\
\text { n3 }=210 \\
\text { No.(\%) or Mean(SD) }\end{array}$ & $P$-value \\
\hline \multicolumn{5}{|l|}{ Infants' characteristics } \\
\hline Infants' age (day) ${ }^{a}$ & $94.0( \pm 51.2)$ & $86.5( \pm 55.7)$ & $102.4( \pm 44.1)$ & 0.001 \\
\hline Male & $239(52.9 \%)$ & $124(51.2 \%)$ & $115(54.8 \%)$ & 0.456 \\
\hline Caesarean section & $200(44.4 \%)$ & $106(44.0 \%)$ & $94(45.0 \%)$ & 0.838 \\
\hline Small for gestational age & $25(5.6 \%)$ & $17(7.1 \%)$ & $8(3.8 \%)$ & 0.136 \\
\hline Preterm & $24(5.3 \%)$ & $15(6.2 \%)$ & $9(4.3 \%)$ & 0.367 \\
\hline \multicolumn{5}{|l|}{ Maternal and family characteristics } \\
\hline Maternal age ${ }^{a}$ & $28.3( \pm 4.63)$ & $28.5( \pm 5.00)$ & $28.0( \pm 4.23)$ & 0.278 \\
\hline Maternal education & & & & 0.008 \\
\hline Primary school and below & $102(22.7 \%)$ & $66(27.4 \%)$ & $36(17.2 \%)$ & \\
\hline Junior high school & $228(50.2 \%)$ & $108(44.6)$ & $120(57.1 \%)$ & \\
\hline Senior high school and above & $122(27.1 \%)$ & $68(28.2 \%)$ & $54(25.8 \%)$ & \\
\hline Maternal nutrition and health knowledge ${ }^{a}$ & $4.48( \pm 1.45)$ & $4.33( \pm 1.41)$ & $4.66( \pm 1.49)$ & 0.020 \\
\hline Number of siblings & & & & 0.031 \\
\hline 0 & $165(36.5 \%)$ & $74(30.6 \%)$ & $91(43.3 \%)$ & \\
\hline 1 & $255(56.4 \%)$ & $151(62.4 \%)$ & $104(49.5 \%)$ & \\
\hline 2 or more & $32(7.1 \%)$ & $17(7.02 \%)$ & $15(7.15 \%)$ & \\
\hline Family asset index ${ }^{a}$ & $-0.005( \pm 1.06)$ & $0.049( \pm 1.09)$ & $-0.068( \pm 1.02)$ & 0.242 \\
\hline \multicolumn{5}{|l|}{ Dependent and independent variables } \\
\hline Exclusive breastfeeding & $72(15.9 \%)$ & $26(10.7 \%)$ & $46(21.9 \%)$ & 0.001 \\
\hline Father functions as secondary caregiver & $97(21.5 \%)$ & $97(40.2 \%)$ & 0 & $<0.001$ \\
\hline Grandmother functions as secondary caregiver & $242(53.5 \%)$ & $108(44.6 \%)$ & $134(63.8 \%)$ & $<0.001$ \\
\hline \multicolumn{5}{|l|}{ Breastfeeding family support } \\
\hline Practical support ${ }^{a}$ & $3.89( \pm 0.70)$ & $3.94( \pm 0.66)$ & $3.83( \pm 0.74)$ & 0.106 \\
\hline Emotional support $^{a}$ & $3.57( \pm 0.40)$ & $3.57( \pm 0.40)$ & $3.57( \pm 0.41)$ & 0.992 \\
\hline Index of maternal decision-making power ${ }^{a}$ & $0.004( \pm 0.75)$ & $-0.09( \pm 0.75)$ & $0.11( \pm 0.73)$ & 0.004 \\
\hline
\end{tabular}

aData are reported as "mean (SD)"

before the survey were recorded, including whether the infant was fed breastmilk, formulas, fresh animal milk, water, juice, etc. Exclusive breastfeeding was defined as that the infant receives only breastmilk, and no other liquids or solids are given (not even water) [1].

Breastfeeding family support is one of the intermediate outcomes. Breastfeeding family support was measured using a scale designed by Zhu Xiu (2013) which contained 9 items. The Cronbach' alpha value of the scale was 0.886 , suggesting adequate internal consistent reliability [38]. For each item, participants were asked to rate their level of agreement on a 5-point Likert-type scale ranging from strongly disagree to strongly agree. This scale can be divided into two dimensions: practical support which include 2 items (such as "my family often prepares food that is good for lactation") and emotional support which include 7 items (such as "I think my family wants me to exclusively breastfeed my child"). We calculated the mean score of each dimension and the higher score indicates stronger perceived family support.

Maternal decision-making power is another intermediate outcome. Maternal decision-making power was measured by the scale adapted from Peterman et al.(2015) and Shroff et al.(2011) [35, 39, 40]. The Cronbach' alpha value of this scale was 0.604 , suggesting an acceptable internal consistent reliability in evaluating decisionmaking power according to Nunnally and Bernstein (1994) [39]. We asked who had the final say on eight household decisions about childcare and household consumption in the family. Options included "respondent", "jointly with others in the household" and "others in the household". Instead of using the raw score total, we coded the answer of "respondent" as " 1 " and others as 
"0". Then we referred to Shroff et al. (2011) and conducted a factor analysis to generate an index indicating the level of maternal decision-making power [35]. A higher score indicated that mother was more powerful in making decision by herself.

\section{Data analysis}

All analyses were performed using Stata 15.0. Descriptive analysis was presented as number (\%) for categorical variables and mean $(S D)$ for continuous variables. We performed student's $t$-tests and reported $p$-values to assess the unadjusted association between father's coresidence and exclusive breastfeeding, breastfeeding family support and maternal decision-making power. Multivariable logistic regressions were used to explore the correlation of the father's co-residence and exclusive breastfeeding, while odds ratios (ORs) and corresponding 95\% confidence intervals $(\mathrm{CIS})$ were reported as a measurement of the risk. We also performed multivariable linear regressions to estimate the correlation of father's co-residence and breastfeeding family support (including practical and emotional support respectively) and maternal decision-making power. Coefficient and corresponding 95\% confidence intervals were also presented. All multivariable regressions controlled the infants' characteristics (age, sex, method of delivery, SGA, whether preterm), maternal characteristics (age, education level and nutrition and health knowledge), family characteristics (number of siblings and family asset index) and county fixed effects. The 0.05 nominal level of significance was used for all statistical tests.

\section{Results}

In total, 452 family-infant pairs were included in our final analysis after excluding 15 (3.2\%) pairs with missing values. Basic characteristics of the participants and their correlations with father's co-residence were reported in Table 1. Specifically, there were more than half of the fathers (53.5\%) co-residing with their families. The mean age of the 452 infants was 94.0 days (range: 6 to 180 days), among which $52.9 \%$ (239) were male. Besides, more than $60 \%$ of the infants had one or more siblings. Participated mothers were 28.3 years old on average (range: 18 to 45 years). In terms of educational level, $50.2 \%$ (228) of the mothers stopped at junior high, and 27.1\% (122) of them had completed senior high school or above. The mean score of maternal nutrition and health knowledge was $4.5(S D=1.5)$ out of 8, meaning that caregivers in rural areas were lack of knowledge about breastfeeding. The exclusive breastfeeding rate was significantly lower in the subgroup of father's coresidency than that of father's non-co-residence (11\% compared to $22 \%, P<0.01$ ). Besides, $40.2 \%$ (97) of co-resident fathers were secondary caregivers, and less grandmothers were secondary caregivers because of father's co-residence

Table 2 Multiple Logistic Regression of Father's Co-residence on Exclusive Breastfeeding ( $N=452)$

\begin{tabular}{|c|c|c|c|c|c|c|}
\hline \multirow[t]{2}{*}{ Dependent variable: exclusive breastfeeding } & \multicolumn{2}{|c|}{ (1) Fathers' co-residence } & \multicolumn{2}{|c|}{$\begin{array}{l}\text { (2) Fathers' involvement when co- } \\
\text { reside }\end{array}$} & \multicolumn{2}{|c|}{ (3) "Crowd out" effect } \\
\hline & OR $(95 \% C l)$ & P Value & OR $(95 \% C l)$ & P Value & OR $(95 \% C l)$ & P Value \\
\hline Father's co-residence ( 1 = yes) & $0.413(0.227-0.750)$ & 0.004 & & & $0.395(0.216-0.724)$ & 0.003 \\
\hline Father functions as secondary caregiver & & & $0.397(0.173-0.912)$ & 0.029 & & \\
\hline Father not functions as secondary caregiver & & & $0.423(0.211-0.848)$ & 0.015 & & \\
\hline Grandmother functions as secondary caregiver & & & & & $0.752(0.413-1.370)$ & 0.351 \\
\hline \multicolumn{7}{|l|}{ Infants' characteristics } \\
\hline Infants' gender ( $1=$ male) & $1.140(0.643-2.023)$ & 0.654 & $1.139(0.642-2.021)$ & 0.657 & $1.153(0.649-2.050)$ & 0.628 \\
\hline Infants' age (day) & $0.994(0.988-1.000)$ & 0.046 & $0.994(0.988-1.000)$ & 0.045 & $0.994(0.998-1.000)$ & 0.048 \\
\hline Caesarean section ( 1 =yes) & $0.682(0.375-1.242)$ & 0.211 & $0.683(0.375-1.244)$ & 0.213 & $0.663(0.363-1.212)$ & 0.182 \\
\hline Small for gestational age ( $1=$ yes) & $2.244(0.548-9.186)$ & 0.261 & $2.240(0.547-9.178)$ & 0.262 & $2.390(0.581-9.843)$ & 0.227 \\
\hline Preterm ( 1 = yes) & $0.295(0.051-1.720)$ & 0.175 & $0.298(0.051-1.751)$ & 0.180 & $0.271(0.046-1.595)$ & 0.149 \\
\hline \multicolumn{7}{|l|}{ Maternal and family characteristics } \\
\hline Maternal age & $0.960(0.887-1.040)$ & 0.317 & $0.961(0.887-1.042)$ & 0.335 & $0.952(0.877-1.033)$ & 0.235 \\
\hline \multicolumn{7}{|c|}{ Maternal education (Primary school and below as reference) } \\
\hline Junior high school & $0.795(0.361-1.752)$ & 0.570 & $0.798(0.361-1.761)$ & 0.576 & $0.799(0.363-1.757)$ & 0.576 \\
\hline Senior high school and above & $0.640(0.253-1.619)$ & 0.346 & $0.641(0.253-1.624)$ & 0.348 & $0.644(0.254-1.633)$ & 0.354 \\
\hline Maternal nutrition and health knowledge & $1.447(1.173-1.785)$ & 0.001 & 1.448 (1.173-1.788) & 0.001 & 1.431 (1.159-1.768) & 0.001 \\
\hline Number of siblings & $1.363(0.792-2.345)$ & 0.264 & 1.362 (0.791-2.344) & 0.265 & $1.347(0.783-2.319)$ & 0.282 \\
\hline Family asset index & 1.149 (0.839-1.573) & 0.386 & $1.147(0.836-1.573)$ & 0.396 & $1.152(0.842-1.575)$ & 0.377 \\
\hline
\end{tabular}

All regressions include county fixed effect 
(45\% compared to $64 \%$ of father's non-co-residence, $P<$ $0.01)$. There was no significant difference in terms of mother's perceived breastfeeding family support, neither practical nor emotional, between the two subgroups, while a significant difference did exist in maternal decisionmaking power $(t=2.86, P=0.004)$.

According to the multivariable regression results presented in Table 2, father's co-residence was significantly and negatively associated with exclusive breastfeeding $(O R=0.413,95 \% C I=0.227-0.750, P=0.004$; column 1$)$, which was consistent with the descriptive analysis. Mothers with fathers' co-residence were further split into two subgroups based on whether fathers function as secondary caregivers or not. Compared with the mothers without fathers' co-residence, the two subgroups of mothers with fathers' co-residence both had significantly lower rate of exclusive breastfeeding $(\mathrm{OR}=0.397,95 \%$ $\mathrm{CI}=0.173-0.912, P=0.029 ; \mathrm{OR}=0.423$, 95\% CI $=0.211-$ $0.848, P=0.015$, respectively; column 2 ), while the odd ratios of the two subgroups were very close $(P=0.830)$. Even grandmother functions as secondary caregiver was taken into consideration, the correlation of father's co-residence and exclusive breastfeeding was still significantly negative $(O R=0.395,95 \% C I=0.216-0.724, P=0.003$; column 3$)$.

We used some intermediate variables to further analyze why there was a negative impact of father's coresidence on exclusive breastfeeding, and results were shown in Table 3. Our data indicated that the father's co-residence was not associated with either maternal perceived practical support $(\beta=0.109,95 \% C I=-0.023-$
$0.241, P=0.105)$ or emotional support $(\beta=0.011,95 \%$ $C I=-0.068-0.090, \quad P=0.791)$. Nevertheless, mothers would have less decision-making power in family decisions when they co-reside with a father $(\beta=-0.196$, 95\% CI $=-0.339--0.053, P=0.007)$, which was also consistent with the descriptive analysis.

\section{Discussion}

This study reports results from a population-based survey examining the influence of father's co-residence on exclusive breastfeeding in western rural China. Our findings showed that the exclusive breastfeeding rate was as low as $16 \%$ in rural China, indicating a large gap from the target of $50 \%$ in 2020 set by Chinese government. When adopted the measurement of predominant breastfeeding, that is, infants who were fed by human milk and water [9], the rate was $42 \%$. Infant's age and maternal nutrition and health knowledge were significantly associated with exclusive breastfeeding, which was consistent with the existing research $[9,11,41]$ while other factors such as caesarean section, maternal education and maternal age not. More attention and greater effort are still needed to promote exclusive breastfeeding in western rural China.

Our findings indicate that father's co-residence was significantly negatively associated with exclusive breastfeeding, even when endogenous explanations, such as infants' age, are taken into consideration. Though some literature from low- and middle-income countries, such as India, documented no correlation between fathers' involvement and better breastfeeding [42], our finding of negative

Table 3 Multiple Linear Regression of Father's Co-residence on Intermediate Variables: Breastfeeding Family Support and DecisionMaking Power ( $N=452)$

\begin{tabular}{|c|c|c|c|c|c|c|}
\hline \multirow[t]{2}{*}{ Dependent variables } & \multicolumn{2}{|l|}{ (1) Practical support } & \multicolumn{2}{|l|}{ (2) Emotional support } & \multicolumn{2}{|c|}{$\begin{array}{l}\text { (3) Index of maternal decision } \\
\text { making power }\end{array}$} \\
\hline & Coefficient $(95 \% \mathrm{Cl})$ & $P$ Value & Coefficient $(95 \% C l)$ & $P$ Value & Coefficient $(95 \% \mathrm{Cl})$ & P Valve \\
\hline Father's co-residence ( 1 = yes) & $0.109(-0.023-0.241)$ & 0.105 & $0.011(-0.068-0.090)$ & 0.791 & $-0.196(-0.339--0.053)$ & 0.007 \\
\hline \multicolumn{7}{|l|}{ Infants' characteristics } \\
\hline Infants' gender (1 = male) & $-0.018(-0.145-0.110)$ & 0.784 & $0.003(-0.073-0.080)$ & 0.931 & $-0.012(-0.150-0.126)$ & 0.861 \\
\hline Infants' age (day) & $-0.001(-0.003--0.000)$ & 0.026 & $-0.001(-0.001-0.000)$ & 0.151 & $0.002(0.000-0.003)$ & 0.010 \\
\hline Caesarean section (1 = yes) & $-0.022(-0.151-0.107)$ & 0.737 & $0.025(-0.052-0.103)$ & 0.519 & $-0.160(-0.300--0.020)$ & 0.025 \\
\hline Small for gestational age ( 1 =yes) & $-0.183(-0.494-0.128)$ & 0.248 & $-0.063(-0.248-0.123)$ & 0.508 & $-0.252(-0.588-0.084)$ & 0.142 \\
\hline Preterm (1 = yes) & $-0.059(-0.262-0.380)$ & 0.718 & $-0.102(-0.090-0.294)$ & 0.296 & $0.023(-0.370-0.325)$ & 0.898 \\
\hline \multicolumn{7}{|l|}{ Maternal and family characteristics } \\
\hline Maternal age & $0.000(-0.016-0.016)$ & 0.962 & $-0.005(-0.014-0.005)$ & 0.329 & $0.000(-0.017-0.018)$ & 0.956 \\
\hline \multicolumn{7}{|c|}{ Maternal education (Primary school and below as reference) } \\
\hline Junior high school & $0.101(-0.078-0.281)$ & 0.268 & $0.017(-0.091-0.124)$ & 0.763 & $-0.049(-0.244-0.145)$ & 0.618 \\
\hline Senior high school and above & $0.204(-0.009-0.417)$ & 0.061 & $0.021(-0.107-0.148)$ & 0.751 & $-0.020(-0.250-0.211)$ & 0.865 \\
\hline Maternal nutrition and health knowledge & $0.057(0.010-0.103)$ & 0.017 & $0.039(0.012-0.067)$ & 0.005 & $0.023(-0.027-0.073)$ & 0.362 \\
\hline Number of siblings & $-0.071(-0.194-0.051)$ & 0.254 & $-0.009(-0.083-0.064)$ & 0.805 & $0.197(0.064-0.330)$ & 0.004 \\
\hline Family asset index & $-0.017(-0.084-0.051)$ & 0.624 & $-0.057(-0.097--0.017)$ & 0.006 & $0.007(-0.066-0.080)$ & 0.851 \\
\hline
\end{tabular}

All regressions include county fixed effect 
correlation is still interesting and contrary to our assumption. Under the encouragement of governments' policies, more migrants are inspired to return home and start their own business, hence fathers are expected to have more chance to co-reside with mothers in the future. Therefore, there is a need to go beyond the aggregate results to examine possible explanations. However, to our knowledge, there are few literatures on the correlation of father's co-residence and mothers' breastfeeding behavior except for the study of Emmott \& Mace (2015). Our findings are consistent with the study of Emmott \& Mace (2015) which conducted in the UK. It documented that the involvement of household chores was related with higher risk of breastfeeding termination [43].

It may because fathers are rarely involved in taking care of infants that cause the negative impact on breastfeeding, since whether fathers migrate to work or not, they carry the financial burden of the entire family and have little time to take care of the mother and infant [44]. Obviously, fathers of co-residence who function as the secondary caregivers will have more opportunity to provide family support than those do not. However, both of the subgroups have a significantly lower and almost the same rate of exclusive breastfeeding than that of father's non-co-residence, indicating a not reasonable explanatory for our findings.

Another explanation may be the "crowd out" effect, that is, father's co-residence may crowd out or replace the support from other family members (such as the grandmothers). The finding that less grandmother functions as the secondary caregiver when father co-reside in the household ( $45 \%$ vs. $64 \%, t=4.15, P<0.01$ ) indicated that the "crowd out" effect do exist, which helped us to understand why the exclusive breastfeeding practices did not change significantly when fathers didn't co-reside. However, the magnitude of coefficient of father's co-residence on exclusive breastfeeding was still negative and almost the same after controlling grandmothers as the secondary caregivers. Hence, the "crowd out" effect is also not the proper reason for the negative impact of father's co-residence.

Our findings also indicate that father's co-residence has no significant impacts on maternal perceived breastfeeding family support, neither practically nor emotionally, which may have two implications. On one hand, mothers don't feel supportive from fathers. This may partly because fathers are less knowledgeable about exclusive breastfeeding and don't know how to assist with breastfeeding challenges $[14,44,45]$. In our sample, the average nutrition and health knowledge score of fathers who function as secondary caregivers was 3.64 $(S D=1.26)$, which was significantly lower than that of the mothers' $(M=4.48, S D=1.45, P<0.01)$. On the other hand, though few improvements are made, paternal support is not too bad or detrimental to decrease the rate of exclusive breastfeeding. Therefore, paternal support is somewhat explanatory but not sufficient for explaining our findings.

Could there exist an additional explanation besides paternal support? The support and resource for successful exclusive breastfeeding should be either from (1) mothers passively receive from the family and society, such as paternal support, or (2) mothers actively seek by themselves. The mother's ability to actively seek support and resource, measured by decision-making power in our context, should be essential while the former one alone is not enough. Our data showed the exclusive breastfeeding rate was $19 \%$ when the index of maternal decision-making power was above the mean, and it significantly decreased to $11 \%$ when the mother was less powerful. Multiple logistic regressions also revealed significantly positive relation between maternal decision-making power and exclusive breastfeeding (Appendix Table 1). The possible and direct explanation is that mothers with lower decision-making power will be less capable to reject the incorrect feeding practices and opinions from fathers. This power for mother will be particularly important when father is not such supportive which we had shown above. Besides, there are also some possible indirect explanations for this finding. First, mothers with lower decision-making power are usually associated with less accessible to necessary resource for better breastfeeding, such as breastfeeding skill trainings or professional consulting. Moreover, less decision-making power is usually associated with less maternal motivation or even more mental health problem [35], which will hinder the mother to overcome the challenges associated with breastfeeding, such as continuing breastfeeding when encounter breast pains. Finally, unlike making decisions alone, more participants in a decision-making process may follow with more time to make decision, more disagreements and more inconsistent actions after decision, which may lead to worse consequence $[6,46]$. Additional research is need to exam the above possible explanation.

\section{Limitations}

There are several limitations in this study. First, only breastfeeding family support are assessed in this study and we did not interview fathers directly, which limit our understanding of how fathers involve in breastfeeding and interact with mothers privately. Besides, though we are trying to give some reasonable explanations to identify how maternal decision-making are associated with exclusive breastfeeding, more in-depth studies are required to better understand the interpersonal dynamics between couples. Second, all samples come from rural areas of western China, which limits external validity with reference to other segments of the population. Finally, we limit the definition of exclusive breastfeeding in our study. As this is a cross-sectional study, exclusive breastfeeding in our study is assessed based on the practices in the last $24 \mathrm{~h}$ prior to the survey date instead 
of within the first 6 month after delivery as WHO recommends. However, our measurement of exclusive breastfeeding is also recommend by WHO [1], so we would not expect this measurement to lead to bias in our conclusions.

\section{Conclusions}

This study found that co-residence with fathers was associated with a significantly lower rate of exclusive breastfeeding in rural western China. Father's coresidence did not improve maternal perceived family support, neither practically nor emotionally. Besides, mother's decision making will become more difficult because of father's involvement. It implies that the low rate of exclusive breastfeeding cannot be attributed to the father's absence, although the father's migration to work in urban areas is common in rural western China.

The findings from this study have important implications for public health policy and practice. Only father's coresidence with the mother is not enough to improve exclusive breastfeeding in rural China. Education aimed at fathers in rural China should be considered and breastfeeding programs should consider the involvement of fathers in the future [47]. On one hand, fathers need more skill-based training on practical information regarding the benefits, process, and management of breastfeeding problems, as well as emotional-targeted strategies like how to express affection, encouragement and admiration to their partner, to provide high quality support for mothers [21, 48-50]. On the other hand, as it is the mother who provides breastfeeding for the infant, they should be fully respected and protected to make their own decisions during lactation.

\section{Appendix}

Table 4 Multiple Logistic Regression of Maternal DecisionMaking Power on Exclusive Breastfeeding ( $N=452)$

\begin{tabular}{|c|c|c|}
\hline $\begin{array}{l}\text { Dependent variable: exclusive } \\
\text { breastfeeding }\end{array}$ & Coefficient $(95 \% \mathrm{Cl})$ & $P$ Value \\
\hline Index of maternal decision-making power & $0.437(0.041-0.834)$ & 0.031 \\
\hline \multicolumn{3}{|l|}{ Infants' characteristics } \\
\hline Infants' gender (1 = male) & $0.113(-0.453-0.680)$ & 0.695 \\
\hline Infants' age (day) & $-0.006(-0.011-0.000)$ & 0.060 \\
\hline Caesarean section ( 1 = yes) & $-0.270(-0.864-0.324)$ & 0.373 \\
\hline Small for gestational age ( 1 =yes) & $0.821(-0.575-2.217)$ & 0.249 \\
\hline Preterm ( 1 = yes $)$ & $-1.416(-3.209-0.378)$ & 0.122 \\
\hline \multicolumn{3}{|l|}{ Maternal and family characteristics } \\
\hline Maternal age & $-0.051(-0.130-0.028)$ & 0.209 \\
\hline \multicolumn{3}{|c|}{ Maternal education (Primary school and below as reference) } \\
\hline Junior high school & $-0.078(-0.855-0.700)$ & 0.845 \\
\hline Senior high school and above & $-0.362(-1.283-0.560)$ & 0.442 \\
\hline Maternal nutrition and health knowledge & $0.387(0.178-0.595)$ & 0.000 \\
\hline Number of siblings & $0.155(-0.386-0.695)$ & 0.575 \\
\hline Family asset index & $0.075(-0.231-0.382)$ & 0.630 \\
\hline
\end{tabular}

The regression includes county fixed effect

\section{Acknowledgements}

We thank the researchers from Stanford University for his help on developing the study protocol and training the enumerators. We are also grateful to all respondents who participated in this study and the enumerators for data collection efforts.

\section{Authors' contributions}

J.N, J.Y, and Y.S conceived the study. J.N, Z.L, J.Y, and Y.S designed the questionnaires. L.Z performed the analysis and interpreted the results with assistance from N.W, W.N., and Z.L. J.N, Y.L, A.J.H, and S.S drafted the manuscript. All authors critically revised the manuscript and approved the final manuscript as submitted.

\section{Funding}

This work was supported by the 111 Project (grant B16031) and National Outstanding Youth Science Fund Project of National Natural Science Foundation of China (grant 72003112)

\section{Availability of data and materials}

The datasets used and analyzed during the current study are available from the corresponding author on reasonable request.

\section{Declarations}

Ethics approval and consent to participate

We followed the principles of the Declaration of Helsinki and received ethical approval from the Institutional Review Board of Shaanxi Normal University (Xi'an, China) and Standard University (Palo Alto, USA, No.44312). All participants signed a written informed consent form to be a part of this study.

\section{Consent for publication}

Not applicable.

\section{Competing interests}

The authors declare that they have no competing interests.

\section{Author details}

${ }^{1}$ Center for Experimental Economics in Education, Shaanxi Normal University, No. 620 West Chang'an Street, Chang'an District, Xian, Shaanxi Province, China. ${ }^{2}$ Business School, Beijing Normal University, Beijing, China. ${ }^{3}$ Elliott School of International Affairs, George Washington University, Washington, D.C., USA.

Received: 19 May 2021 Accepted: 14 October 2021

Published online: 02 November 2021

\section{References}

1. Victora CG, Bahl R, Barros AJD, França GVA, Horton S, Krasevec J, et al. Breastfeeding in the 21st century: epidemiology, mechanisms, and lifelong effect. Lancet. 2016;387(10017):475-90. https://doi.org/10.1016/S0140-6736(1 5)01024-7

2. WHO/UNICEF. Global Nutrition Targets 2025: Breastfeeding Policy Brief (WHO/NMH/NHD/14.7). Geneva: World Health Organization; 2014. https://a pps.who.int/iris/handle/10665/149022. Accessed 30 Sep 2021

3. China Development Research Foundation. Investigation report on influencing factors of breastfeeding in China. 2018. https://cdrf.org.cn/jjh/ pdf/mu.pdf. Accessed 18 Apr 2020.

4. Duan Y, Yang Z, Lai J, Yu D, Chang S, Pang X, et al. Exclusive breastfeeding rate and complementary feeding indicators in China: a National Representative Survey in 2013. Nutrients. 2018;10(2):249-58. https://doi.org/1 0.3390/nu10020249.

5. UNICEF. Maternity Leave Legislation in Support of Breastfeeding: Case Studies around the World. 2019. https://www.who.int/publications/i/item/ WHO-NMH-NHD-19.25. Accessed 30 Sep 2021.

6. Wallenborn JT, Perera RA, Wheeler DC, Lu J, Masho SW. Workplace support and breastfeeding duration: the mediating effect of breastfeeding intention and self-efficacy. Birth. 2019;46(1):121-8. https://doi.org/10.1111/birt.12377. 
7. UNICEF China. Population status of children in China in 2015-facts and figures. 2017. https://www.unicef.cn/en/reports/population-status-childrenchina-2015. Accessed 13 Apr 2020.

8. State Council. Notice of the health and health commission on issuing the maternal and child safety action plan (2018-2020) and healthy child action plan (2018-2020) 2018. http://www.gov.cn/gongbao/content/2018/ content_5327474.htm. accessed April 24, 2020.

9. Fang Z, Liu Y, Wang H, Tang K. The patterns and social determinants of breastfeeding in 12 selected regions in China: a population-based crosssectional study. J Hum Lact. 2019;36(3):436-47. https://doi.org/10.1177/ 0890334419868156

10. Ogbo F, Akombi B, Ahmed K, Rwabilimbo A, Ogbo A, Uwaibi N, et al. Breastfeeding in the community-how can partners/fathers help? A systematic review. Int J Environ Res Public Health. 2020;17(2):413-26. https:// doi.org/10.3390/ijerph17020413.

11. Ruan Y, Zhang Q, Li J, Wan R, Bai J, Wang W, et al. Factors associated with exclusive breast-feeding: a cross-sectional survey in Kaiyuan, Yunnan, Southwest China. PLoS One. 2019;14(10):e0223251. https://doi.org/10.1371/ journal.pone.0223251.

12. Hunter T, Cattelona G. Breastfeeding initiation and duration in first-time mothers: exploring the impact of father involvement in the early postpartum period. Health Promot Perspect. 2014;4(2):132-6. https://doi.org/10. 5681/hpp.2014.017. eCollection 2014.

13. Lok KYW, Bai DL, Tarrant M. Family members' infant feeding preferences, maternal breastfeeding exposures and exclusive breastfeeding intentions. Midwifery. 2017;53:49-54. https://doi.org/10.1016/j.midw.2017.07.003.

14. Merritt $R$, Vogel $M$, Ladbury $P$, Johnson S. A qualitative study to explore fathers' attitudes towards breastfeeding in south West England. Prim Health Care Res Dev. 2019;20:e24. https://doi.org/10.1017/S146342361 8000877.

15. Tohotoa J, Maycock B, Hauck YL, Howat P, Burns S, Binns CW. Dads make a difference: an exploratory study of paternal support for breastfeeding in Perth, Western Australia. Int Breastfeed J. 2009;4(1):15. https://doi.org/10.11 86/1746-4358-4-15.

16. Rempel LA, Rempel JK. Partner influence on health behavior decisionmaking: increasing breastfeeding duration. J Soc Pers Relat. 2004;21(1):92111. https://doi.org/10.1177/0265407504039841.

17. Rempel LA, Rempel JK, Moore KCJ. Relationships between types of father breastfeeding support and breastfeeding outcomes: father breastfeeding support types. Matern Child Nutr. 2017;13(3):e12337. https://doi.org/10.1111/ mcn.12337.

18. Rempel LA, Rempel JK. The breastfeeding team: the role of involved fathers in the breastfeeding family. J Hum Lact. 2011;27(2):115-21. https://doi.org/1 $0.1177 / 0890334410390045$.

19. National Bureau of Statistics. Migrant Workers Monitoring Survey Report 2018. 2018.http://www.stats.gov.cn/tjsj/zxfb/201904/t20190429_1662268. html Accessed April 24, 2020.

20. Yue A, Gao J, Yang M, Swinnen L, Medina A, Rozelle S. Caregiver depression and early child development: a mixed-methods study from rural China. Front Psychol. 2018;9. https://doi.org/10.3389/fpsyg.2018.02500.

21. Bulemela J, Mapunda H, Snelgrove-Clarke E, MacDonald N, Bortolussi R. Supporting breastfeeding: Tanzanian Men's knowledge and attitude towards exclusive breastfeeding. Int Breastfeed J. 2019;14(1):52-9. https:// doi.org/10.1186/s13006-019-0244-7.

22. Grassley J, Eschiti V. Grandmother breastfeeding support: what do mothers need and want? Birth. 2008;35(4):329-35. https://doi.org/10.1111/j.1523-53 6X.2008.00260.X.

23. Negin J, Coffman J, Vizintin P, Raynes-Greenow C. The influence of grandmothers on breastfeeding rates: a systematic review. BMC Pregnancy Childbirth. 2016;16(1):91. https://doi.org/10.1186/s12884-016-0880-5.

24. Zhao H, Liu R, Shi H, Zuo P. Impact of the family support system on breastfeeding: a literature review. Mod Prev Med. 2018;45:1235-8.

25. Bennett $A E$, Kearney JM. Insights from fathers in Ireland on their ability to support their breastfeeding partner. Proc Nutr Soc. 2017;76(OCE1):E21. https://doi.org/10.1017/S0029665117000210.

26. Chang $Y$, Valliant $M$, Bomba AK. Gender differences in knowledge and attitude regarding breastfeeding: breastfeeding knowledge and attitude. Int J Consum Stud. 2012;36(3):342-51. https://doi.org/10.1111/j.1470-6431.2010. 00994.x.

27. Yu M, Fan D, Qiu J, Du Y. The influencing factors of Father's breastfeeding attitude. Chin Nurs Manag. 2019;19:1330-3.
28. Tsai S-Y. Influence of partner support on an employed Mother's intention to breastfeed after returning to work. Breastfeed Med. 2014;9(4):222-30. https://doi.org/10.1089/bfm.2013.0127.

29. Uludağ E, Öztürk S. The effect of partner support on self-efficiency in breastfeeding in the early postpartum period. Am J Fam Ther. 2020;48(2): 211-9. https://doi.org/10.1080/01926187.2019.1697973.

30. Cunningham K, Ruel M, Ferguson E, Uauy R. Women's empowerment and child nutritional status in South Asia: a synthesis of the literature. Matern Child Nutr. 2015;11(1):1-19. https://doi.org/10.1111/mcn.12125.

31. Eustachio Colombo EC Patricia. Mothers' intra-household decision making autonomy and its associations with the dietary diversity of 6-24 month old children in Majune, Mozambique: a cross-sectional study: Uppsala University; 2015.

32. Liu $X, L i Y$. The influence of migration on the family status of married rural women: based on the data of the third National Survey on the status of Chinese women in Shaanxi. J Chin Women's Stud. 2013;(05):34-42.

33. Yin H, Wu Y, Wang S, Wang Y, Wang $H$. The Effects of Child Gender on Women's Family Decision-making Power in Poverty-stricken Rural Areas. Chin Rural Econ. 2018;No.397:110-25.

34. Shroff. Maternal autonomy is inversely related to child stunting in Andhra Pradesh, India. Matern Amp Child Nutr. 2009;5(1):64-74. https://doi.org/1 0.1111/j.1740-8709.2008.00161.x.

35. Shroff MR, Griffiths PL, Suchindran C, Nagalla B, Vazir S, Bentley ME. Does maternal autonomy influence feeding practices and infant growth in rural India? Soc Sci Med. 2011;73(3):447-55. https://doi.org/10.1016/j.socscimed.2 011.05.040.

36. National Bureau of Statistics. Human miracle: statistical monitoring report on poverty alleviation in China. Beijing: China Statistics Press; 2021.

37. National Bureau of statistics. China Statistical Yearbook-2019. 2019. http:// www.stats.gov.cn/tjsj/ndsj/2019/indexch.htm. Accessed May 6, 2020.

38. Zhu X, Li Y, Lu H. Reliability and validity of breastfeeding family support questionnaire. Chin J Mod Nurs. 2013;19(07):775-9.

39. Nunnally JC, Bernstein IR. Psychometric theory. New York: McGraw-Hill; 1994.

40. Peterman A, Schwab B, Roy S, Hidrobo M, Gilligan D. Measuring Women's decision making: Indicator choice and survey design experiments from cash and food transfer evaluations in Ecuador, Uganda, and Yemen; 2015.

41. Li J, Duan Y, Bi Y, Wang J, Lai J, Zhao C, et al. Predictors of exclusive breastfeeding practice among migrant and non-migrant mothers in urban China: results from a cross-sectional survey. BMJ Open. 2020;10(9):e038268. https://doi.org/10.1136/bmjopen-2020-038268.

42. Yourkavitch JM, Alvey JL, Prosnitz DM, Thomas JC. Engaging men to promote and support exclusive breastfeeding: a descriptive review of 28 projects in 20 low- and middle-income countries from 2003 to 2013. J Health Popul Nutr. 2017;36(1):43. https://doi.org/10.1186/s41043-017-0127-8.

43. Emmott EH, Mace R. Practical support from fathers and grandmothers is associated with lower levels of breastfeeding in the UK millennium cohort study. PLoS One. 2015;10(7):e0133547. https://doi.org/10.1371/journal.pone. 0133547.

44. Tokhi M, Comrie-Thomson L, Davis J, Portela A, Chersich M, Luchters S. Involving men to improve maternal and newborn health: a systematic review of the effectiveness of interventions. PLoS One. 2018;13(1):e0191620. https://doi.org/10.1371/journal.pone.0191620.

45. Brown A, Davies R. Fathers' experiences of supporting breastfeeding: challenges for breastfeeding promotion and education: fathers and breastfeeding. Matern Child Nutr. 2014;10(4):510-26. https://doi.org/10.1111/mcn.12129.

46. Marks E, Grant C, de Castro T, Bandara D, Wall C, Morton S. Agreement between future parents on infant feeding intentions and its association with breastfeeding duration: results from the growing up in New Zealand cohort study. Int J Environ Res Public Health. 2018;15(6):1230. https://doi. org/10.3390/ijerph15061230.

47. Tadesse K, Zelenko O, Mulugeta A, Gallegos D. Effectiveness of breastfeeding interventions delivered to fathers in low-and middle-income countries: a systematic review. Matern Child Nutr. 2018;14(4):e12612. https:// doi.org/10.1111/mcn.12612.

48. Sherriff N, MPCp AFBPS, Panton C, Hall V. A new model of father support to promote breastfeeding. Community Pract J Community Pract Health Visit Assoc. 2014;87:20-4.

49. Bich TH, Hoa DTP, Ha NT, Vui LT, Nghia DT, Målqvist M. Father's involvement and its effect on early breastfeeding practices in Viet Nam. Matern Child Nutr. 2016;12(4):768-77. https://doi.org/10.1111/mcn.12207. 
50. Su M, Ouyang Y. Father's role in breastfeeding promotion: lessons from a quasi-experimental trial in China. Breastfeed Med. 2016;11(3):144-9. https:// doi.org/10.1089/bfm.2015.0144.

\section{Publisher's Note}

Springer Nature remains neutral with regard to jurisdictional claims in published maps and institutional affiliations.

Ready to submit your research? Choose BMC and benefit from:

- fast, convenient online submission

- thorough peer review by experienced researchers in your field

- rapid publication on acceptance

- support for research data, including large and complex data types

- gold Open Access which fosters wider collaboration and increased citations

- maximum visibility for your research: over $100 \mathrm{M}$ website views per year

At $\mathrm{BMC}$, research is always in progress. 